\title{
Self-monitoring Composite Rods for Sustainable Construction
}

\author{
Cristiana Gonilho-Pereira, Emilija Zdraveva, Raul Fangueiro, S. Lanceros-Mendez, \\ Said Jalali, and Mário de Araújo \\ University of Minho, School of Engineering, Campus de Azurém, \\ 4800-001 Guimarães, Portugal \\ cristiana.pereiralcivil.uminho.pt, emilijia_zdravevaenet.hr, \\ rfangedet.uminho.pt, lancerosefisica.uminho.pt, \\ saidecivil.uminho.pt, maraujo@det.uminho.pt
}

\begin{abstract}
This paper presents the development and properties assessment of braided reinforced composite rods (BCR) able to both reinforce and monitor the stress state of concrete infrastructures. The research study aims at understanding the tensile behaviour and self-monitoring ability of composite rods reinforced by a textile structure - braided structure with core reinforcement - for civil engineering applications, namely for concrete internal reinforcement, as a steel substitute, in order to improve structures safety and sustainability. Seven types of braided composite rods have been produced using an author patented technique based on a modified conventional braiding machine. The tensile properties of the braided reinforced composite rods were evaluated in order to identify the type(s) of fibre(s) to be used as core reinforcement. BCR have been tested under bending while the variation of the electrical resistance was simultaneously monitored.
\end{abstract}

Keywords: sustainability, composite rod, tensile, self-monitoring, concrete.

\section{Introduction}

The concrete construction industry deals every day with the deterioration of concrete structures which compromises its security, safety and construction sustainability. Nowadays a large number of bridges, buildings and other structural elements require rehabilitation and repair and its maintenance have become an increasingly serious problem.

The corrosion of steel reinforcing rebar is the dominant cause of concrete structure degradation. The most effective way to prevent corrosion of steel rebar is the use of a orrosion resistant reinforcing material, such as fiber-reinforced-polymer (FRP) composites. The types of fiber-reinforced-polymer composites best suited for the reinforcement of concrete are those providing high strength, high stiffness, and environmental compatibility with concrete.

Nevertheless, the interest in the sustainability of concrete structures has increased and monitoring and maintaining their safety has become a main goal. To achieve this main goal monitoring systems that can be applied to the reinforced concrete elements

S. Tenreiro de Magalhães, H. Jahankhani, and A.G. Hessami (Eds.): ICGS3 2010, CCIS 92, pp. 193-201, 2010.

(c) Springer-Verlag Berlin Heidelberg 2010 
are required. The damage sensing is conventionally performed by attached or embedded damage sensors, such as optical fibers, acoustic sensors, etc. however these sensors have limited application because of high cost, low durability, and limited sensing volume and spatial resolution. One solution is that the materials themselves can possess a self-diagnosing function for fracture; thus, strong and heavy design, complex and expensive equipment and numerous sensors becomes unnecessary, the so called self-diagnosing structural materials $[1,2]$.

Structural materials have evolved from materials that are mechanically strong (such as steel) to materials that are both strong and lightweight (such as composite materials) and most recently to materials that are both strong and self-monitoring [1]. By definition, a self-monitoring material is one which can sense its own strain and damage. It can be considered a smart material. However, in contrast to smart materials such as optical fibers, piezoelectric sensors, etc., the self-monitoring materials are themselves structural materials. Thus, instead of structures rendered smart by embedded or attached sensors, self-diagnosing structural materials are intrinsically smart, so there is no need of embedded or attached sensors. For example, the basic principle of the carbonaceous smart structural material to detect strain or damage lies in the electrical conductivity of the carbon fibers, as already known from the literature [2]. As the carbon fibres are electrically conductive, the composite itself can exhibit electrical properties, which will depend upon strain, damage and temperature. The self monitoring material will, in this way, provide determination of the strain or damage by measuring the change in the electrical resistance during real time loading [3].

Most commercial FRPs are rod-like elements that are pultruded, shaped, and treated so that surface texture provide mechanical adherence with concrete [4]. Besides pultrusion, fibre reinforced composite rods can also be produced using braiding techniques [5], Braiding is a low cost technique allowing in-plane multiaxial orientation, conformability, excellent damage tolerance and allows core reinforcement. Moreover, braiding allows the production of ribbed structures and a wide range of mechanical properties may be improved when the core braided structures are reinforced with the appropriate type of fibers [6].

The current work is concerning the development of braided reinforced composite rods for civil engineering applications, namely for concrete internal reinforcement and monitoring.

\section{Experimental Work}

The objective of the experimental work presented in this paper, is the evaluation of the influence of the type of core reinforcement fibres on the tensile behaviour of braided composite rods and the assessment of its monitoring capabilities.

\subsection{Braided Composite Rod Production}

Braiding technique is one of the most ancient production processes of textile structures. The basic principle of braiding is the mutual intertwining of yarns. Braids are fibrous structures resulting of the yarns crossing in diagonal direction and can be tubular or flat, namely if they have round/oval cross section or not. 
Core reinforced braided structures are braided tubular structures presenting, beside two systems of yarns moving helically, a third one that introduces yarns on the braid axial direction. This third system of yarns may be composed by different types of fithe mechanical performan-made. The axial reinforcement fibres are responsible for the braided structure itself is rather poor

Braided composites rods are produced

minor modifications, developed by the Fib in a conventional braiding machine with sity of Minho, allowing its impreg the Fibrous materials Research Group, at Univertechnology with minor adaptations, ribbed colymeric matrix. Hence, using braiding gle step according to an author patented technique rods may be produced in a sinbraiding machine.

\subsection{Raw Materials}

Seven different braided composite rods were produced using polyester fibres for the braided structure production, E-glass, carbon and HT polyethylene fibres as braided structure core reinforcement, and a polyester resin was used for the core reinforced braided structure impregnation. Braided composite rods were produced maintaining "orcement fibre, accore geometry and linear density and varying the type of core rein-

Braing to Table 1.

as well as with two and three types of fibre with a single type of reinforcement fibres Table 1 presents the percentage of each type of varying the percentage of each one. the total linear density of the core reinforcement.

Table 1. Braided composite rods composition

\begin{tabular}{cccc}
\hline \multirow{2}{*}{ Rod type } & \multicolumn{3}{c}{ Type of core reinforcement fibre } \\
\cline { 2 - 4 } & E-Glass fibre [\%] & Carbon fibre [\%] & $\begin{array}{c}\text { HT polyethylene } \\
\text { fibre [\%] }\end{array}$ \\
\hline 1 & 100 & - & - \\
2 & 77 & 23 & - \\
3 & 53 & 47 & - \\
4 & - & 100 & - \\
5 & 50 & 45 & 5 \\
6 & 52 & 45 & 3 \\
7 & 75 & 22 & 3 \\
\hline
\end{tabular}

The type and the amount of fibre were chosen to compare the tensile behavior of composite rods, as showed in Table 1. Rod type 2,3 and 4 were tested regarding their monitoring ability based on the electrical resistance measurement during simultaneous application of a deformation in a cyclic three-point bending test. 


\subsection{Properties Evaluation}

Table 2 presents the rod diameter and the fibre mass fraction of the reinforcement fibres of each rod produced. In order to evaluate the mass fraction of the clifferent braided composite rods produced, tests were conducted according to the Portuguese Standard NP 2216/1988 (determination of mass loss by calcinations of glass fibre reinforced plastics).

Rods diameter varies from 5.27 to $6.40 \mathrm{~mm}$ and the mass fraction of the core reinforcement fibres ranges from 31.8 and $40.6 \%$. According to Table 2, there is no relationship between the rod diameter variation and the volume fraction of the core reinforcement fibres. Therefore, the resin content varies from rod to rod.

During the curing period of the polyester resin, the core reinforcement fibres were subjected to a pre-Ioad of $100 \mathrm{~N}$. In order to evaluate the mechanical performance of the different braided reinforced composite rods produced, tensile tests were carried out according to ASTM D 3916-94 standard, with a crosshead speed of $5 \mathrm{~mm} / \mathrm{min}$. A postload of $50 \mathrm{KN}$ was applied to the rods prior to performing the tensile tests. Table 3 presents the average values of the tensile test results obtained for each rod type.

Table 2. Braided reinforced rods physical properties

\begin{tabular}{ccc}
\hline Rod type & Rod diameter [mm] & $\begin{array}{c}\text { Mass fraction } \\
\text { (reinforcement fibres) [\%] }\end{array}$ \\
\hline 1 & 5,50 & 40,6 \\
2 & 5,27 & 35,3 \\
3 & 5,75 & 31,8 \\
4 & 6,40 & 33,3 \\
5 & 6,00 & 35,6 \\
6 & 5,98 & 32,7 \\
7 & 5,78 & 33,7 \\
\hline
\end{tabular}

Table 3. Tensile test results obtained for the different braided reinforced composite rods

\begin{tabular}{ccccc}
\hline $\begin{array}{c}\text { Rod } \\
\text { Type }\end{array}$ & $\begin{array}{c}\text { Tensile strength } \\
{[\mathrm{MPa}]}\end{array}$ & $\begin{array}{c}\text { Extension at } \\
\text { failure }\end{array}$ & $\begin{array}{c}\text { Tensile strength at } \\
0.2 \%[\mathrm{MPa}]\end{array}$ & $\begin{array}{c}\text { Modulus of } \\
\text { Elasticity [GPa] }\end{array}$ \\
\hline 1 & 485,35 & 0,01701 & 110,73 & 55,36 \\
2 & 766,70 & 0,01416 & 157,05 & 78,52 \\
3 & 740,41 & 0,01178 & 148,96 & 74,48 \\
4 & 747,77 & 0,01183 & 192,58 & 96,29 \\
5 & 679,45 & 0,01105 & 167,84 & 83,92 \\
6 & 652,77 & 0,01098 & 162,17 & 81,09 \\
7 & 690,99 & 0,01438 & 146,40 & 73,20 \\
\hline
\end{tabular}


The testing procedure carried on the BCR to evaluate the monitoring ability was based on the electrical resistance measurement during simultaneous application of a deformation in a cyclic three-point bending test. Cyclic three-point bending tests were carried on a Universal Testing Machine - Autograph IS (Shimadzu) 500N, with a crosshead speed of $0,3 \mathrm{~mm} / \mathrm{min}$. The electrical resistance measurement was carried on a digital multi-meter (Agilent, 84401A). The electrical signal was acquired through Representative examples of the two type samples with silver paint.
Rolden wires attached the cros section

Representative examples of the two types of behavior obtained for the mechanical and electrical results from the cyclic loading three-point bending tests and the simulaneous electrical resistance measurements are presented in Figures 1 and 2 for the $3 \mathrm{CR}$ samples tested. Figure I presents the increase in the electrical resistance with inreasing displacement. Figure 2 shows curves showing the decrease of the electrical esistance with increasing deformation. In general, the electrical resistance during oading and unloading increases linearly at lower displacement values and nonlinearly t thigher ones. In the case of the inverse response, during decrease of the electrical reistance and deformation increase, the nonlinearity is less evident. Whether it was a everse or inverse response in both cases the tested sample showed the change of the lectrical resistance in proper compliance with the change of its deformation. The ain factors influencing the type of response of each sample was the relative position $f^{*}$ fibers and the resin inside the rods, or more precisely the carbon fiber place-
ein $i_{1 .}$ along the length of the rods.

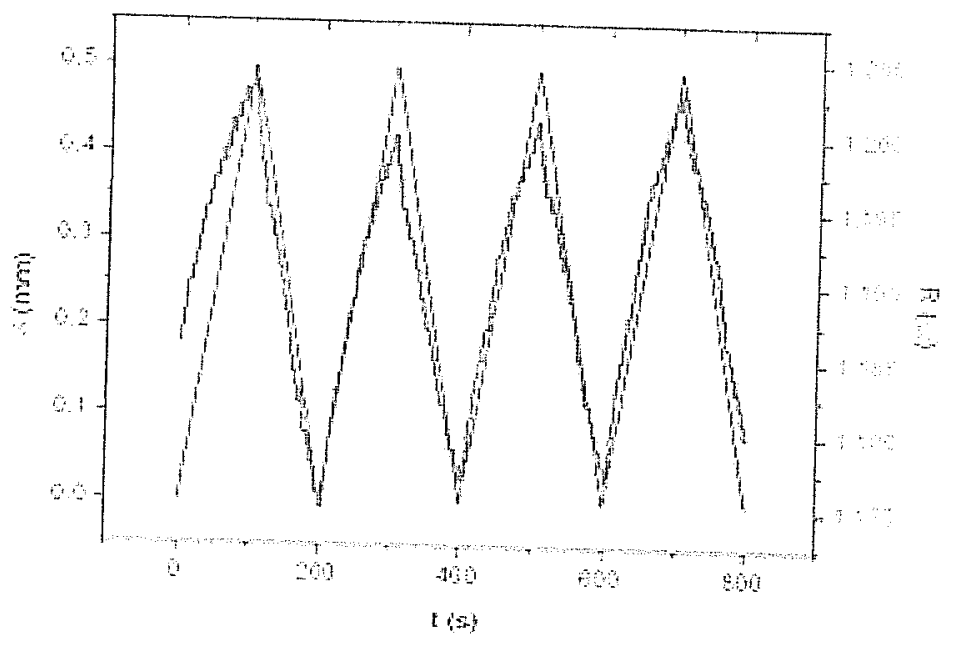

Tisplacement, resistance change and time dependence for type $\mathrm{BCR}_{4}(100 \%$ of carbon);
response of tested samples

The cross-sections present variations in the carbon fiber placement once the fibers not placed uniformly on one side of the cross-section and, more important, the disuution is not the same on both cross-sections of a rod sample. In this situation, reasing of the resistance with increasing deformation occurred when the carbon fis are placed on the tensile side and the opposite behavior when their placement is 


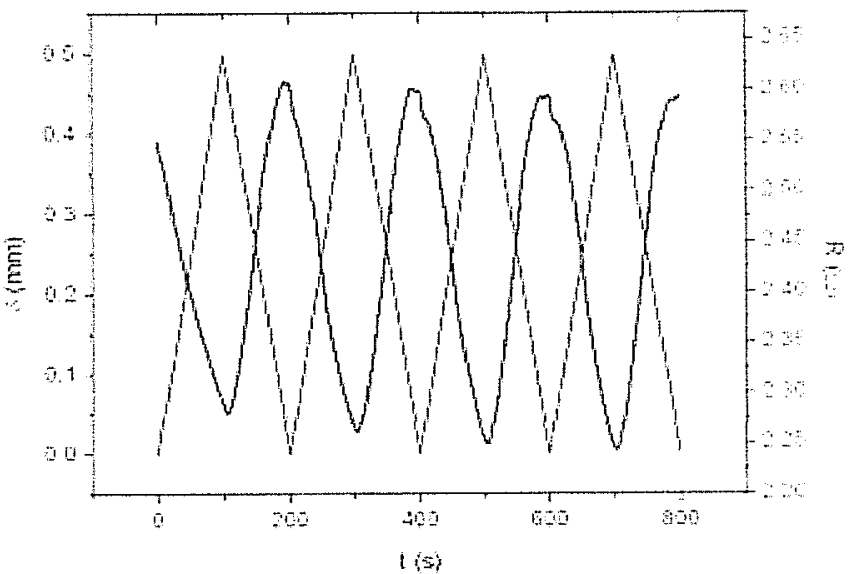

Fig. 2. Displacement, resistance change and time dependence for type $\mathrm{BCR}_{2}(77 \%$ of glass, $23 \%$ of carbon); Negative response of tested samples

on the compression side of the bending rod. This issue indicates the relevance of controlling carbon placement uniformly along the length of the rod. This is a difficult step on the production process, which sometimes results in non-uniformity along the length of the rods as the braiding process rotates the fibers.

On the other hand, for each rod, the cycles are reproducible, confirming the reliable sensing property of the rods. The difference between the peak values in each of the cycles is around $0,01 \Omega$ to $0,02 \Omega$.

The range of the initial electrical resistance for the BCR 2 varies from $1,46 \Omega$ to $3,92 \Omega$, for BCR 3 from $1,11 \Omega$ to $1,50 \Omega$ and for BCR 4 from $0,80 \Omega$ to $1,37 \Omega$.

Furthermore, for the comparison of the sensing behavior differentiation due to carbon fiber content, the strain $\varepsilon\left(\times 10^{-2}\right)$ and the fractional resistance change $\Delta R / R_{0}$ of the three types of BCR are presented in Table 4 . The strain is calculated from the displacement and the fractional resistance change is calculated from the electrical resistance change, the values from the two parameters are presented over time of 100,300 , 500 and 700 seconds.

As can be seen in Table 5, the gage factor for BCR 2 is almost five times higher than that for BCR 3 and BCR 4. The gage factor of type BCR 3 is slightly higher.

The gage factor, known as the strain-sensing factor, shows the sensing behavior of the composite rod samples. It increases with the decreasing of the carbon fiber percentage. This means that BCR 2 has the most reliable monitoring behavior.

It is interesting to compare the resulted gage factors of the BCRs with other materials for the same applications. For example in a study of a carbon nanotube strain sensors, it was investigated that the range of the gage factor was between 1 and 5, depending on the percentage of the single walled carbon nanotube (SWCNT) polymer composites, and better sensitivity was established in the range of 3 to $10 \mathrm{wt} \%$ of the SWCNT in the polymer [6]. 
Another study, investigating a multi walled carbon nanotube (MWCNT) films used as strain sensing material, reported that the calculated gage factors were 2.3.09 and 3,76 , respectively, for 3 types of samples [7].

Taking these examples into comparison with the investigated samples in this study, it is evident that the gage factors calculated for the composite rods are all less than 1 , much smaller than the example studies set forth above. The reason for these small values of the gage factors would be, as mentioned, the higher percentage of the carbon component. On the other hand, the main advantage of the present materials is the superior reinforcing capabilities and therefore the combination of reinforcing and sensing capabilities.

Table 4. Strain and fractional resistance change of BCR (mean values)

\begin{tabular}{|c|c|c|c|c|c|c|c|c|c|}
\hline \multirow[b]{2}{*}{$\begin{array}{l}\text { Rod } \\
\text { Type }\end{array}$} & \multirow{2}{*}{$\begin{array}{c}\text { Cycle } \\
\text { No. } \\
\text { t (s) } \\
\text { Sample } \\
\text { No. }\end{array}$} & \multicolumn{2}{|c|}{$\begin{array}{c}1 \\
100\end{array}$} & \multicolumn{2}{|c|}{$\begin{array}{c}2 \\
300\end{array}$} & \multicolumn{2}{|c|}{$\begin{array}{c}3 \\
500\end{array}$} & \multicolumn{2}{|c|}{$\begin{array}{c}4 \\
700\end{array}$} \\
\hline & & $\begin{array}{c}\varepsilon \\
\times 10^{-} \\
2\end{array}$ & $\begin{array}{c}\Delta \mathrm{R} / \\
\mathrm{R}_{0}\end{array}$ & $\begin{array}{c}\varepsilon \\
\times 10^{-} \\
2\end{array}$ & $\begin{array}{l}\Delta \mathrm{R} / \\
\mathrm{R}_{0}\end{array}$ & $\begin{array}{c}\varepsilon \\
\times 10^{-}\end{array}$ & $\begin{array}{c}\Delta \mathrm{R} / \\
\mathrm{R}_{0}\end{array}$ & $\begin{array}{c}\varepsilon \\
\times 10^{-} \\
2\end{array}$ & $\begin{array}{l}\Delta \mathrm{R} / \\
\mathrm{R}_{0}\end{array}$ \\
\hline \multirow{2}{*}{2} & $\begin{array}{c}\mathrm{Xm} \\
1,2,3 \\
\end{array}$ & 0,48 & $-0,10$ & 0,48 & $-0,11$ & 0,48 & $-0,12$ & 0,48 & $-0,12$ \\
\hline & $\begin{array}{c}12,13 \\
14\end{array}$ & 0,47 & 0,08 & 0,47 & 0,07 & 0,47 & 0,07 & 0,47 & 0,06 \\
\hline \multirow{2}{*}{3} & $3,7,12$ & 0,48 & 0,04 & 0,48 & 0,02 & 0,48 & 0,01 & 0,48 & 0,01 \\
\hline & $6,10,13$ & 0,48 & $-0,06$ & 0,48 & $-0,07$ & 0,48 & $-0,07$ & 0,48 & $-0,07$ \\
\hline 4 & $5,7,12$ & 0,55 & 0,02 & 0,55 & 0,01 & 0,55 & 0,01 & 0,55 & 0,01 \\
\hline
\end{tabular}

Table 5. Gage factors (GF) and squared regression values $\left(\mathrm{R}^{2}\right)$ of established trend equations

\begin{tabular}{|c|c|c|c|c|c|c|}
\hline \multirow{2}{*}{$\begin{array}{l}\text { Rod } \\
\text { Type }\end{array}$} & \multicolumn{2}{|c|}{ GF } & \multirow{2}{*}{ Xm } & \multicolumn{2}{|c|}{$\mathbf{R}^{2}$} & \multirow{2}{*}{ Response } \\
\hline & $1^{*}$ & $2 *$ & & 1 & 2 & \\
\hline \multirow{3}{*}{2} & 0,58100 & 0,46312 & 0,52206 & 0,98965 & 0,99602 & \multirow{2}{*}{ Positive } \\
\hline & 0,09554 & 0,12951 & 0,11253 & 0,95651 & 0,97279 & \\
\hline & $-0,28869$ & $-0,34058$ & $0,3 \overline{1464}$ & 0,99218 & 0,97288 & Negative \\
\hline \multirow{3}{*}{3} & 0,16095 & 0,15806 & 0,15951 & 0,98918 & 0,99668 & \multirow{2}{*}{ Positive } \\
\hline & 0,03847 & 0,07018 & 0,05433 & 0,98339 & 0,98172 & \\
\hline & $-0,14084$ & $-0,16380$ & 0,15232 & 0,93925 & 0,96892 & Negative \\
\hline \multirow[b]{2}{*}{$T$} & 0,03581 & 0,03702 & 0,03415 & 0,97118 & 0,99305 & Positive \\
\hline & $-0,07451$ & $-0,07684$ & 0,07568 & 0,99448 & 0,98699 & Negative \\
\hline
\end{tabular}




\subsection{Braided Composite Rod and Steel Rebar Tensile Performance Comparison}

Considering the different composite rods tensile strength, extension at failure, tensile

BCR 4 presents the and modulus of elasticity, some conclusions can be withdrawl. interesting one, although rod 1 presting tensile performance while BCR 1 presents the less

$B C R 2$ and 7, presenting presents the highest reinforcement fibre mass fraction. significantly different tensile behoviour, amount of E-glass and carbon fibres, presents fraction. Although rod 7 presents aviour, mainly due to the reinforcement fibre mass is lower than in rod 2.

For compositer the presence and increasing of 5 , with the same amount of E-glass and carbon fibres, bre mass fraction, promotes an increathylene fibre, as well as the increase of the fi-

Although the tensile performcreasing of the rod tensile performance.

the reinforcement fibre merformance of the braided composite rods is influenced by fibre has a significantly higher iffon, one can conclude that the type of reinforcement

When compared to ther influence.

composite rods reinforced by carbobars currently used in the construction industry, sile strength. Current Portugues, glass and polyethylene fibres present higher tenA500NR/ER have values of tensilese steel rebars, A235NL, A400NR/ER and spectively. BCR 1 is the only comple strength of $360 \mathrm{MPa}, 460 \mathrm{MPa}$, and $550 \mathrm{MPa}$, re$550 \mathrm{MPa}$. Even though the tensile braided composite rods is higher strength of E-glass, carbon and HT polyethylene

However, composite higher than that of steel rebars.

that of steel rebars, $210 \mathrm{GPa}$.

\section{Conclusions}

The braided composite rods diameter varies due to the core reinforcement fibres used and to the resin mass fraction. There is no relationship between the rod diames used the mass fraction of the reinforcement fibres. Braided composite rod reinforced by $77 \%$ E-glass and $23 \%$ carbon fibres, presents the highest tensile strength is presented by the composite rod tensile strength. The lowest Analysing the extension at failure pomposite rod reinforced by $100 \%$ E-glass fibre. E-glass, $46 \%$ carbon and $3 \%$ HT polyethymeter, composite rod reinforced by $52 \%$ Once again, the composite rod reinforthylene presents the lowest extension at failure. value.

Braided composite rod reinforced by $100 \%$ carbon fibre presents the highest yield stress and, therefore, the highest modulus of elasticity. Composite rod reinforced by

The BCRs that presents the lowest values in both parameters.

est amount of E-glass fibre. Among the rods with the are those who present the lowhighest tensile performance. ence than the fibre mass fraction in the of reinforcement fibre used has higher influ- 
In what concerns the sensing periormance of braided reiniorced rods using giass and carbon, it can be concluded that all three types of BCR used can stand as a selfsensing material. The electrical contact set-up was effective in the purpose of resistance stabilization and measurent.Two types of responces were obtained by the BCR. Positive GF, in the case of the carbon fibreplaced in the area subjected to tensile and negative GF, in the case of the carbon fibre placed in the compressive side of the rod. Furthermore, the GF increased with decreasing carbon fiber content. The most reliable monitoring behavior was given by BCR 2 (77\% glass, $23 \%$ carbon) with the smallest carbon fiber content.

\section{References}

[1] Muto, N., Arai, Y., Shin, S.G., Matsubara, H., Yanagida, H., Sugita, M., Naka-tsuji, T.: Hybrid composites with self-diagnosing function for preventing fatal fracture. Comp. Sci. and Tech. 61, 875-883 (2001)

[2] Chung, D.D.L.: Self-monitoring structural materials. Composite Materials Re-search Laboratory, State University of New York, Buffalo, NY 14260-4400, USA (1997)

[3] Bakis, C.E., Nanni, A., Terosky, J.A., Koehler, S.W.: Self-monitoring, pseudo - ductile, hybrid FRP reinforcement rods for concrete applications. Comp. Sci. and Tech. 61, 815$823(2001)$

[4] Lees, J.M.: Fibre.reinforced polymers in reinforced and prestressed concrete applications: moving forward. Prog. Struct. Eng. Mater. 3, 122-131 (2001)

[5] Soebroto, H.B., Pastore, C.M., Ko, F.K.: Engineering design of braided structural fibreglass composite. In: 6th Annual Conference, Advanced Composites, Structural Composites: Design and Processing Technology, Detroit (1990)

[6] Fangueiro, R., Sousa, G., Araújo, M., Gonilho Pereira, C., Jalali, S.: Core reinforced composite armour as a substitute to steel in concrete reinforcement. In: International Symposium Polymers in Concrete - ISPIC 2006, Universidade do Minho, Guimarães, Portugal, April 2-4 (2006)

[7] Kang, I., et al.: Introduction to carbon nanotube and nanofiber smart materials. Composites: part B 37, 382-394 (2006)

[8] Li, X., Levy, C., Elaadil, L.: Multiwalled carbon nanotube film for strain sensing. Nanotechnology 19,045501 (7pp) (2008) 